$51 /-63$

6032

AIAA-94-1187-CP

\title{
Meeting the Challenges of Installing a Mobile Robotic System
}

\author{
Celeste DeCorte \\ Cyberomotion, Incorporated \\ Salem, Virginia
}

\begin{abstract}
$\underline{\text { Abstract }}$
The challenges of integrating a mobile robotic system into an application environment are many. Most problems inherent to installing the mobile robotic system fall into one of three categories:
\end{abstract}

- The physical environment location(s) where, and conditions under which, the mobile robotic system will work

- The technological environment - external equipment with which the mobile robotic system will interact

- The human environment personnel who will operate and interact with the mobilc robotic system

The successful integration of a mobile robotic system into these three types of application environment requires more than a good pair of pliers. The tools for this job include: careful planning. accuratc measurement data (as-built drawings), complete technical data of systems to be interfaced, sufficient time and attention of key personnel for training on how to operate and program the robot, on-site access during installation, and a thorough understanding and appreciation - by all concerned - of the mobile robotic system's role in the security mission at the site, as well as the machine's capabilities and limitations.

Patience, luck, and a sense of humor are also uscful tools to keep handy during a mobile robotic system installation.

This paper will discuss some specific examples of problems in cach of the three catcgorics, and explore approaches to solving these problems. The discussion will draw from the author's experience with on-site installations of mobile robotic systems in various applications.

Most of the information discussed in this paper has come directly from knowledge learned during installations of Cybermotion's SR2 security robots. A large part of the discussion will apply to any vehicle with a drive system, collision avoidance, and navigation sensors, which is, of course, what makes a vehicle autonomous. And it is with these sensors and a drive system that the installer must become familiar in order to forcsec potential trouble areas in the physical, technical, and human cnvironment.

\section{Physical Environment:}

What you see is not always what your robot sees. Picture a hallway 5 feet wide, carpeted, and 30 feet long. Problem or no problem? Usually it's not as easy as you think. I can walk down this hallway easily, why can't the robot. Turn out the lights or have a few drinks then try to walk down the hallway. Stubbed your toe didn't you. We now have established that even humans can have a problem walking down a hallway, and we have a self-righting mechanism: arms. What are the important aspects of the physical environment to a robot? Anything that can affect navigation or collision avoidance, such as floor surfaces, walls, and obstacles.

Now that we know the potential hazards, let's start from the ground up. Different floor surfaces causc problems that are specific to each robot and are mostly dependent upon the type of drive system. If you could require, by Jaw, that all buildings use only one floor 
covering, which one would you choose? carpets? wood? tile? or that bumpy pebble-type floor? Any robot installer in her or his right mind would say tile. It's mostly level, no bumps, and has a low coefficient of friction. Tile and poured concrete floors exist in great quantities in the manufacturing world, but not so much in the corporate world. Carpeting has its ups and downs and is very deceiving. Most installers see thick plush carpet and hit the roof; they see indoor-outdoor carpet and get warm fuzzies. Maybe not! Each carpet will have its own unique problems related mostly to the under flooring, which you can't see. Some carpets will give back a sonar image; some will slip on the floor; some will act just like a tiled flat floor. Until you've run over it a few times, you'll never guess what troubles the noor will create. Carpet may affect your navigation through slippage, your collision avoidance through sonar reflection, and your drive system through increased frictions. Other than that, carpet is a wonderful surface for robots. Most of the same problems will recur for one of those pebble aggregate concrete floors. They are very uneven and generate a great vibrational analysis atmosphere for your system. This floor could be very hazardous to your electronics. No floor is cver simple. Even poured concrete may have slopes, cracks, and dips. Although working on thesc surfaces may not be simple, remember that all these floor types have been -- and are being -- traversed by autonomous vehicles.

After you've mastered the floor in your building, it's time for the walls. I'm sure you are wondering how walls could cause a problem. It's the type of material they are made of, as well as what people put on them, that create your problems. Sound-absorbent cubicles, sheet rock, and concrete make up most walls in buildings.

Sound-absorbent cubicles may create a problem depending upon the wave-length of your sonar. These walls do not reflect all wavelengths of sound, and that is a problem. At the frequencies used by Cybermotion this is seldom a problem. Another problem with these cubicles is that they are easy to move and may never be in the same location from one day to the next; therefore, they are not good navigational walls. If you have no other options they are better than not navigating at all.

Sheet rock is wonderful, usually the best surface that you can imagine. The only down side is that everyone loves to mount items on this type of wall. Door moldings, fire hoses, fire extinguishers, water fountains, and many other objects. The resulting corner reflectors, as I like to call them, give an excellent sonar echo return that makes mountains out of mole hills. In a wide hallway where your vehicle has room to pass these objects will not be a problem. But in tight hallways you may choose to avoid these areas rather than reduce your safety by reducing collision ranges.

The third type of wall is cinderblock. These concrete building blocks are full of holes and bumps. This rough surface generates some interesting echoes and their effect definitely relates to how you use sonar in your system. The Cybermotion SR2 can be modified to ignore the false images that are returned from such a rough surface. If you don't navigate using walls then this part doesn't really matter.

So far we've discussed what's below, (floor) and what's to the side, (wall). All that's left is what's in front of you, (objects). Walls and floors affected our drive system, our collision avoidance, and our navigation sensors. Obstacles affect our collision avoidance sensors. There are two different types of obstacles: fixed and floating. Every building has it's unique fodder or floating obstacles. These include: mops, displays, decorations, etc . During your walk through of the facility you will see where these obstacles will generally be located and you can plan accordingly. If you can find out what day is trash day I recommend that you visit the day before to see everything at it's worst. People are creatures of habit, and once you learn their habits, you can plan around them. In one particular instance a hallway was full of furniture. I thought it would be moved into someone's office, but six months later I have been assured that it is still in the hallway and is not going anywhere in the near future. Fixed obstacles are no problem, but make sure that the vehicle has sufficient clearance to move around them.

Once you figure out where you want your vehicle to travel based upon your information about floors, walls, and obstacles, the last piece to the physical environment you need is an accurate map of the facility showing fixed obstacles and hallways. You may be surprised to know that "as-built" drawings rarely exist; they are more like "as-planned." You may need to do some measuring to get the maps up to date. Programming and debugging are much simpler with an accurate map. 
Once we've mastered the building or physical environment, our system is operating on single floors, our paths are debugged, and the vehicle is working perfectly, it's time to tie everything together through the technical environment.

\section{Technical Environment:}

The technical environment is made up of external equipment with which the mobile robotic system will interact. These can include: doors, elevators, lighting systems, etc. The question here is: what must I control to run all of my paths with one robot? At Cybermotion we don't normally offer robots cquipped with door openers and button pushers as an option. So far these options are extremely cost prohibitive and power hungry. Other companics may have this option available. So the trick is to call the elevator to the right floors and get the door at the end off the hallway to open and close at will. Many different approaches have been taken to solve these problems. There is the "We'll make sure that the door is propped open when the vehicle is running" approach. These good intentions can work if it is someone's specific job to make sure that the appropriate doors are open and that you don't violate any fire codes. Otherwise it will not get done all the time, and you have to develop a solution. You could choose to install motion detectors to automatically open and close for any movement. This option requires minimal installation but is a potential sccurity problem if you want to restrict access to the area. Your options are limited by your customer requirements. One option is an automatic door with IR or RF receiver and a transmitter on the vchicle to signal when the robot requires the door to be open and closed. This option requires integration of inexpensive hardware on your vehicle. If hardware integration is not desirable, door access can bc controlled at the base station computer. This option requires a communications link between the door mechanism and the computer. Part of the program sent to the vehicle would be to open the door at a certain time in the program. Each option is viable; it's just a matter of deciding which one best matches the job.

Personnel intervention, RF or IR link, and base computer control, the options discussed above, can be applied to most technical environments. Even elevators can be handled in this manner. Pcrsonnel intervention should be used only if there is already an elevator operator in the building. Working with elevators will require a controls interface provided by the elevator manufacturer. Another option is to install a poking device with vision recognition to ensure that the vehicle gets off on the correct floor. This poking mechanism will greatly increase the cost of the robot. Both the IR or RF and the computer base station will require information to be received and transmitted to the elevator controls. You will need an architecture that will operate like your button-pushing finger. Consider all the mechanisms with which the system will be required to interact, and pick a solution that can best handle all interfaces. Some day the button-pushing finger may best suit the job, but that day has yet to come. There is one more interface that requires a special interface. The people interaction.

\section{Human Environment:}

The Human environment is made up of everyone that could possibly come in contact with the robot. As you might have guessed, most of the biggest problems you will have to overcome are in this environment. There are three basic groups of pcople that you will need to work with: those who do not interact, those who modify the environment, and those who opcrate the system. Every step of the way, you will have people to train and you will have to explain the operation of your system to everyone from the janitor to the president of the company. Each system comes with a certain amount of training. Usually the more you know the more effective your system. What you don't know can hurt you just as much as what you do know.

People who come into your facility while the robot is running; such as visitors, employees that are working late, and contractors, are those who do not interact with your system. These people typically exhibit a facial expression of amazement followed by the long stare. This curiosity response as I like to call it only lasts for about one minute. After such time they consider the vehicle part of there environment and ignore it like everything else. 
Those who modify the cnvironment, such as cleaning people, can inadvertently creatc a diflicult operating environment for vehicles. Buckets, mops, trash cans, boxes, and vacuum cleaners are among the obstacles that you may have to avoid or maneuver around. The best solution allows everyone to complete his or her job with minimal changes. Habits are hard to break. If Mr. Clean always leaves his tub-o-trash in front of the elevator, this is a problem. Give him a little information about how the vehicle operates, and possibly a note from his supervisor, you can start to work replacing habits that may inhibit vehicle operation with habits that facilitate operation. Once the habit is changed, it's all down hill.

The operator may be the easiest -- or the hardest -individual to get to cooperate. Some people love technology and will be hanging on every word about the system. Somc are absolutcly frightencd. Some just belicve that robots are replacing people; such people can make your life miserable. Those who love technology are very helpful and usually fast learners, although their curiosity usually gencrates the need for a few solutions. "I wonder if it can roll over or " What happens if I push __. Curiosity can kill a robot. Those who have a slight fear of technology can become your best operator. Patience is required up front, but once they see that the robot does not fall apart when they touch it, they get the bug to learn. Best of all they become great teachers to those who come on board after you leave. Then you have the potential spoilers. You cannot force technology on people. Time may bring these people around to your way of thinking, but the best you can hope for is that they don't want to sabotage your project.

Robot installation is a test of skill, knowledge, finagling, and endurance. When an installation is up and running, and you're no longer needed for a helping hand, it is a wonderful feeling that I hope you will get to experience. 